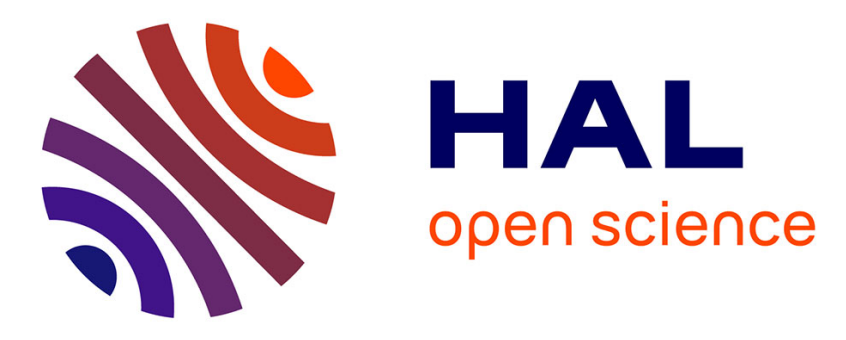

\title{
Modern humans sex estimation through dental tissue patterns of maxillary canines
}

Cecilia García-Campos, María Martinón-Torres, Marina Martínez de Pinillos,

Mario Modesto-Mata, Laura Martín-Francés, Bernardo Perea-Pérez, Clément Zanolli, José María Bermúdez de Castro

\section{To cite this version:}

Cecilia García-Campos, María Martinón-Torres, Marina Martínez de Pinillos, Mario ModestoMata, Laura Martín-Francés, et al.. Modern humans sex estimation through dental tissue patterns of maxillary canines. American Journal of Physical Anthropology, 2018, 167 (4), pp.914-923. 10.1002/ajpa.23715 . hal-02296691

\section{HAL Id: hal-02296691 https://hal.science/hal-02296691}

Submitted on 25 Feb 2021

HAL is a multi-disciplinary open access archive for the deposit and dissemination of scientific research documents, whether they are published or not. The documents may come from teaching and research institutions in France or abroad, or from public or private research centers.
L'archive ouverte pluridisciplinaire HAL, est destinée au dépôt et à la diffusion de documents scientifiques de niveau recherche, publiés ou non, émanant des établissements d'enseignement et de recherche français ou étrangers, des laboratoires publics ou privés. 


\section{Modern humans sex estimation through dental tissue patterns of maxillary canines}

Cecilia García-Campos María Martinón-Torres Marina Martínez de Pinillos Mario ModestoMata Laura Martín-Francés Bernardo Perea-Pérez Clément Zanolli José María Bermúdez de Castro

Funding information: Dirección General de Investigación of the Spanish Ministerio de Economía y Competitividad (MINECO/FEDER), Grant/Award Number: CGL2015-65387-C3-1, 3-P; The European Social Funds; Consejería de Educacion; of the Junta de Castilla y León; Atapuerca Foundation; Leakey Foundation

\footnotetext{
Abstract

Objectives

Dental tissue proportions of human permanent canines is one of only a few sexually dimorphic features that is present in childhood and maintained in adults, offering the opportunity for this to be used in sex determination. This study assesses dental tissue volumes and surface areas of maxillary permanent canines in a sample of known sex to provide new data and to explore the potential of these variables as reliable sexual estimators.

Materials and methods

The teeth studied here derive from 56 individuals (27 females and 29 males) of known sex and age, and of different geographic origins. The teeth were scanned and three-dimensional (3D) measurements (volumes and surface areas) were obtained. In addition, a discriminant function analysis was applied.

Results

The results presented here concur with those previously published in relation to both size and dental tissue patterns. Male maxillary canines have a greater dentine component, whereas female enamel is thicker, leading to a difference in dental size in favor of males. Discriminant functions were calculated using these histological variables successfully identifying sex in between $87.5 \%$ and $93.75 \%$ of the known-sex hold-out sample, with $92.3 \%$ correctly assigned when all functions were applied together.

Discussion
} 
The present study supports that methods for sex determination based on dental tissue measurements can achieve high allocation accuracies, being especially useful in the case of subadults or when no other appropriate method is available.

\section{INTRODUCTION}

Sexual variation in the human skeleton is of great concern for anthropologists. Sexual dimorphism, the differences in size and form between males and females of the same species, is also observed in dentition (Feeney et al., 2010; Harris, Hicks, \& Barcroft, 2001; Hillson, 1996a; Saunders, Chan, Kahlon, Kluge, \& FitzGerald, 2007; Schwartz \& Dean, 2005; Stroud, Buschang, \& Goaz, 1994; Zilberman \& Smith, 2001). In modern human populations, males have larger tooth crowns than females, which has allowed the development of different sexual assignment methodologies based on linear measurements of coronal diameters (Cardoso, 2010; Karaman, 2006; Peckmann, Logar, Garrido-Varas, Meek, \& Pinto, 2015; Zorba, Moraitis, Eliopoulos, \& Spiliopoulou, 2012).

Among the teeth, mandibular canines have been widely used in sexual identification (Acharya \& Mainali, 2007; Garn, Lewis, \& Kerewsky, 1967; Hillson, 1996a; Lund \& Mörnstad, 1999; Rao, Rao, Pai, \& Kotian, 1989; Schwartz \& Dean, 2005). The measurement of the mesiodistal (MD) diameter and mandibular intercanine distance consists of a simple method that has been used to establish sex identity, particularly in adults (Rao et al., 1989). In recent years, the assessment of coronal tissue proportions has aroused great interest due to the influence that sexual chromosomes and hormones seem to have on them (Alvesalo, 1997; Alvesalo \& Portin, 1980; Alvesalo, Tammisalo, \& Hakola, 1985; Guatelli-Steinberg, Sciulli, \& Betsinger, 2008; Pentinpuro, Pesonen, Alvesalo, \& Lähdesmäki, 2017; Zilberman \& Smith, 2001). Studies of enamel and dentine surface areas, measured on buccolingual (BL) planes of the mandibular canine crowns, have suggested that males have more dentine than their female counterparts, with the latter exhibiting greater enamel thicknesses (Feeney et al., 2010; Saunders et al., 2007; Schwartz \& Dean, 2005). A recent study using three-dimensional (3D) measurements (volumes and surface areas) of hard dental tissues supports results previously obtained: "Sexual dimorphism of mandibular canine size is mainly due to males having a greater dentine volume, whereas sex differences in enamel dimensions do not make a large contribution to overall tooth size" (García-Campos et al., 2018). These differences were large enough to allow the authors to 
determine sex with $92.3 \%$ accuracy, through the use of a combination of seven discriminant functions. These results demonstrate that mandibular canines should continue to be considered as "key teeth" for personal identification, especially when other skeletal elements are fragmented and/or DNA is unavailable.

Sexual dimorphism of maxillary canines has been also described, although in contrast with its mandibular counterpart, studies focused on this tooth class are scarce. As in the case of lower canines, upper canine crown dimensions have been shown to be larger in males than in females, which has once again been used in the development of different multivariate methodologies to explore sex differentiation (Ateş, Karaman, Işcan, \& Erdem, 2006; Ditch \& Rose, 1972; Işcan \& Kedici, 2003; Pereira, Bernardo, Pestana, Santos, \& de, 2010). However, only a few studies have quantified the dental tissue proportions of this tooth class in the modern human population. In the majority of these studies, two-dimensional (2D) quantification of the amount of enamel and dentine was performed using physical cross sections (Smith et al., 2012; Smith, Olejniczak, Reh, Reid, \& Hublin, 2008) and virtual sections obtained from 3D rendered models (Feeney et al., 2010). Nevertheless, despite its potential for assessing sexual dimorphism, a comparison between male and female maxillary canines was performed only in the latter study, in which it was shown that males have significantly greater values for dentine area and enamel-dentine junction (EDJ) length, whereas no significant differences were recorded in the enamel area and thickness. Although the published data is unique, the study carried out by Feeney et al. (2010) has two main limitations: the small sample size, which was no more than 20 individuals per tooth class; and the methodology employed. Given that enamel thickness is not homogenously distributed in the crown, conventional 2D measurements of ideal BL section planes may not be a reliable estimator of 3D whole-crown variability. This means that some measurements may be overestimated or underestimated when only 2D variables from the crown are considered (Benazzi et al., 2014; García-Campos et al., 2018; Olejniczak, Smith, et al., 2008). 3D measurements have been considered as a more precise method of evaluating tissue proportions as they counteract the effect of dimensional loss suffered by classic 2D estimations (Benazzi et al., 2014; Feeney, 2009; García-Campos et al., 2018; Molnar, Hildebolt, Molnar, Radovcic, \& Gravier, 1993; Shellis, Beynon, Reid, \& Hiiemae, 1998).

The current study is the first to apply microtomographic imaging to a broad forensic sample of known sex, to determine the degree of sexual dimorphism in maxillary canine 3D dental tissue 
proportions. The objectives of this work are to: (a) assess the variability within sexes in the

volumes and surface areas of the permanent upper canine dental tissues; (b) explore its potential for reliable sex determination through the application of discriminant function analysis; and (c) contrast our results against those obtained in lower canines by García-Campos et al. (2018).

\section{MATERIALS AND METHODS}

Details of the sample studied, the scanning parameters, and the methodology employed here can be found below and in García-Campos et al. (2018).

The teeth studied here derive from 56 individuals (27 females and 29 males) of known sex and age, and of different geographic origins. The sample was selected from the anthropological collections housed at the Escuela de Medicina Legal of Madrid (Spain) and the University of Pretoria (South Africa), as well as from a sample of dental extractions carried out in different clinics in Sudan (Elamin \& Liversidge, 2013). The sample was designed to obtain a similar representation of individuals with African and European origin in the female and male subsamples. In the present study, only one antimere per individual was included in the analysis. The studied upper canines showed a degree of wear equal to or smaller than three (Molnar, 1971), which is characterized by the obliteration of the apex at the incisal border and the presence of a dentine point instead.

The specimens were scanned in three facilities: the Phoenix v/tome/x s (GE Measurement \& Control) microtomographic system housed in the Microscopy Laboratory of the Centro Nacional de Investigación sobre la Evolución Humana (CENIEH) in Burgos (Spain); the CTP-Mlab microCT located in the Multidisciplinary Laboratory of the International Centre for Theoretical Physics (ICTP) in Trieste (Italy); and in the South African Nuclear Energy Corporation (Necsa), Pelindaba, using Nikon XTH 225 ST equipment. The output images had a voxels size ranging between 17 and $50.8 \mu \mathrm{m}$. The subsequent image processing of each of the teeth was performed using Amira 6.0.0 software (Visage Imaging, Inc., San Diego, CA). Dental tissues (enamel and dentine-pulp complex) were semiautomatically segmented using the Watershed Segmentation Tool and through manual editing. A Non-Local Means filter was also applied. Small fractures and cracks were virtually filled in.

Dental tissue volumes and surface areas described in Olejniczak, Smith, et al. (2008), Olejniczak, Tafforeau, Feeney, and Martin (2008), Skinner, Gunz, Wood, and Hublin (2008), and Skinner, 
Wood, et al. (2008) were quantified following the protocol put forward by García-Campos et al. (2018) (Figure 1), which was based on a previous study by Benazzi et al. (2014). The variables and indices included were: volume of the enamel cap $\left(\mathrm{Ve}, \mathrm{mm}^{3}\right)$; volume of the coronal dentine including the coronal pulp (Vcdp, $\mathrm{mm}^{3}$ ); the surface area of the enamel-dentine junction (EDJS, in $\left.\mathrm{mm}^{2}\right)$; the outer surface of the enamel cap $\left(\mathrm{OES}, \mathrm{mm}^{2}\right)$; 3D average enamel thickness index

$(3 \mathrm{DAET}=\mathrm{Ve} / \mathrm{EDJS}, \mathrm{mm})$; the 3D relative enamel thickness index $(3 \mathrm{DRET}=3 \mathrm{DAET} /$

) $\times 100$, free scale); and the relative dentine volume defined as the percentage of coronal volume that is dentine and pulp $(\mathrm{Vcdp} / \mathrm{Vc}=\mathrm{Vcdp} / \mathrm{Vc} \times 100$, percentage scale). In addition, the volume of the root dentine including the pulp $\left(\mathrm{Vr}, \mathrm{mm}^{3}\right)$, the coronal volume $\left(\mathrm{Vc}, \mathrm{mm}^{3}\right)$ and the basal surface of the crown $\left(\mathrm{BS}, \mathrm{mm}^{2}\right.$ ) were measured and subsequently used to compute the total tooth volume $\left(\mathrm{Vt}=\mathrm{Vc}+\mathrm{Vr}, \mathrm{mm}^{3}\right)$ and the relative coronal volume $(\mathrm{Vc} / \mathrm{Vt}=\mathrm{Vc} / \mathrm{Vt} \times 100$, percentage scale). A detailed explanation of each of the variable and indices can be found in García-Campos et al. (2018).

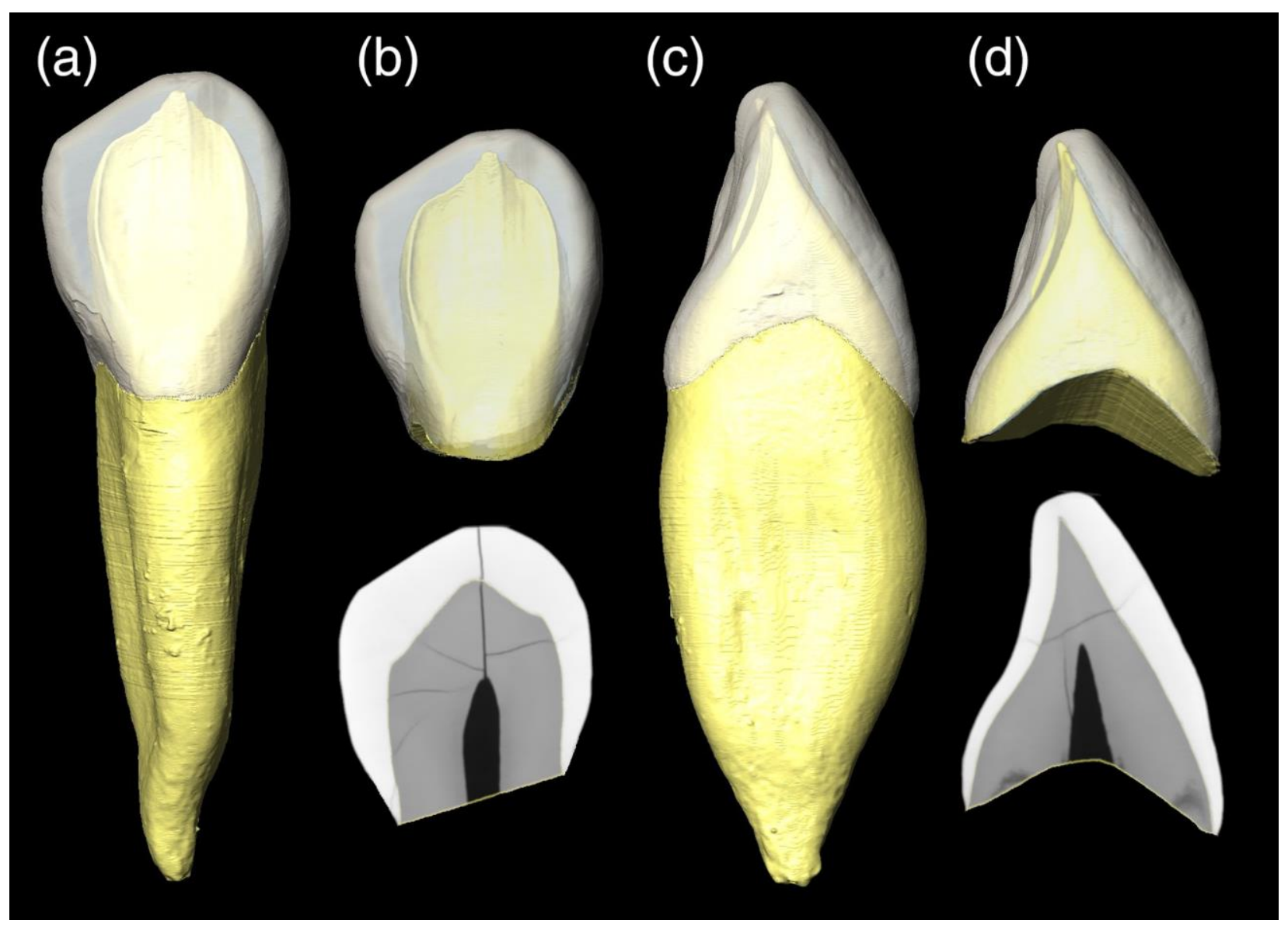


Figure 1. Crown isolation. The canine is orientated in its anatomical position: (a) lingual view and (c) mesial view. Then, a straight line between the maximum enamel extensions is drawn in the mesiodistal stack of slices (b) defining the lower limit of the crown and giving rise to concave curve in the buccolingual slices (d). In that way, the crown is limited on the base by a curve with a smooth surface which isolates it from the root volume.

Statistical analyses were performed using SPSS software (v. 18.0, SPSS Science, Inc.). First, standard descriptive statistics were calculated for each variable. The normal distribution and the equal variance assumption were assessed using the Kolmogorov-Smirnov one-sample test and Levene's test respectively. Analysis of variance (ANOVA) and covariance (ANCOVA) were employed to examine the possible differences between males and females. When equal variance could not be assumed a Student's $t$ test was applied instead. Means were considered to be significantly different at $\alpha=0.05$ level. In addition, a discriminant function analysis (DFA) was performed to generate a set of univariate and multivariate functions from the $3 \mathrm{D}$ variables. The whole sample was divided into two sub-samples for statistical purposes. A total of 40 slightly worn teeth (19 females, 21 males) were used to create the discriminant functions, whereas 16 teeth ( 8 females, 8 males) were used as a hold-out sample. The functions created were tested in the original sample and the leave-one-out method was chosen to calculate the cross-validation error index. The percentage of correct allocation accuracy in determining sex was also calculated for the hold-out sample: females and males separately, and for the whole of the sample. Lastly, only the equations with a high percentage of correct assignments were selected and included in this study.

\section{RESULTS}

Table 1 and Figure 2 provide the descriptive statistics for the 3D dental tissue measurements

(both absolute data and associated indices) for males and females, together with a summary of the results of statistical comparisons of means (ANOVA, Student's $t$ test and ANCOVA).

Tables 2 and 3 present, respectively, the discriminant functions obtained in this study and their accuracy at correctly assigning sex. 
Table 1. Descriptive statistics, analysis of variance (ANOVA) and analysis of covariance (ANCOVA) results for the three-dimensional variables measured on slightly worn maxillary canines (mean and standard deviation, $S D$ ). When equal variance could not be assumed, a Student's $t$ test was applied (*)

\begin{tabular}{|c|c|c|c|c|c|c|c|c|c|c|}
\hline \multirow[b]{2}{*}{ Measurement } & \multicolumn{3}{|c|}{ Female } & \multicolumn{3}{|c|}{ Male } & \multirow{2}{*}{$\begin{array}{l}\text { ANOVA } \\
\text { Sig. }\end{array}$} & \multicolumn{3}{|c|}{ ANCOVA } \\
\hline & $n$ & Mean & $S D$ & $n$ & Mean & $S D$ & & Sig. & $\begin{array}{l}\text { Female } \\
\text { mean }\end{array}$ & $\begin{array}{l}\text { Male } \\
\text { mean }\end{array}$ \\
\hline $\mathrm{Vc}$ & 27 & 223.94 & 35.93 & 29 & 286.86 & 57.05 & .00 & - & - & - \\
\hline $\mathrm{Vr}$ & 27 & 299.37 & 59.93 & 29 & 420.98 & 81.11 & .00 & - & - & - \\
\hline $\mathrm{Vt}$ & 27 & 523.31 & 93.41 & 29 & 707.84 & 121.52 & .00 & - & - & - \\
\hline $\mathrm{Ve}$ & 27 & 109.96 & 20.04 & 29 & 128.80 & 34.77 & $.016 *$ & - & - & - \\
\hline Vcdp & 27 & 113.98 & 18.57 & 29 & 158.07 & 26.95 & .00 & .02 & 130.61 & 142.58 \\
\hline EDJS & 27 & 115.25 & 11.32 & 29 & 142.43 & 17.81 & $.00 *$ & - & - & - \\
\hline OES & 27 & 174.43 & 18.64 & 29 & 204.31 & 29.61 & $.00 *$ & - & - & - \\
\hline BS & 27 & 33.08 & 3.72 & 29 & 43.82 & 5.61 & .00 & .00 & 36.33 & 40.79 \\
\hline Vtdp & 27 & 413.34 & 76.35 & 29 & 579.05 & 97.92 & .00 & .00 & 489.16 & 508.45 \\
\hline \multicolumn{11}{|l|}{ Index } \\
\hline $\mathrm{Vc} / \mathrm{Vt}$ & 27 & 43.016 & 2.53 & 29 & 40.58 & 4.46 & $.00 *$ & - & - & - \\
\hline 3DAET & 27 & 0.95 & 0.12 & 29 & 0.90 & 0.17 & .17 & - & - & - \\
\hline 3DRET & 27 & 19.71 & 2.52 & 29 & 16.61 & 2.97 & .00 & - & - & - \\
\hline Vcdp/Vc & 27 & 50.94 & 3.36 & 29 & 55.54 & 4.64 & .00 & - & - & - \\
\hline OES/EDJS & 27 & 1.51 & 0.07 & 29 & 1.43 & 0.08 & .00 & - & - & - \\
\hline
\end{tabular}

- Dimensions in millimeters. Significant $p$ values in bold. 

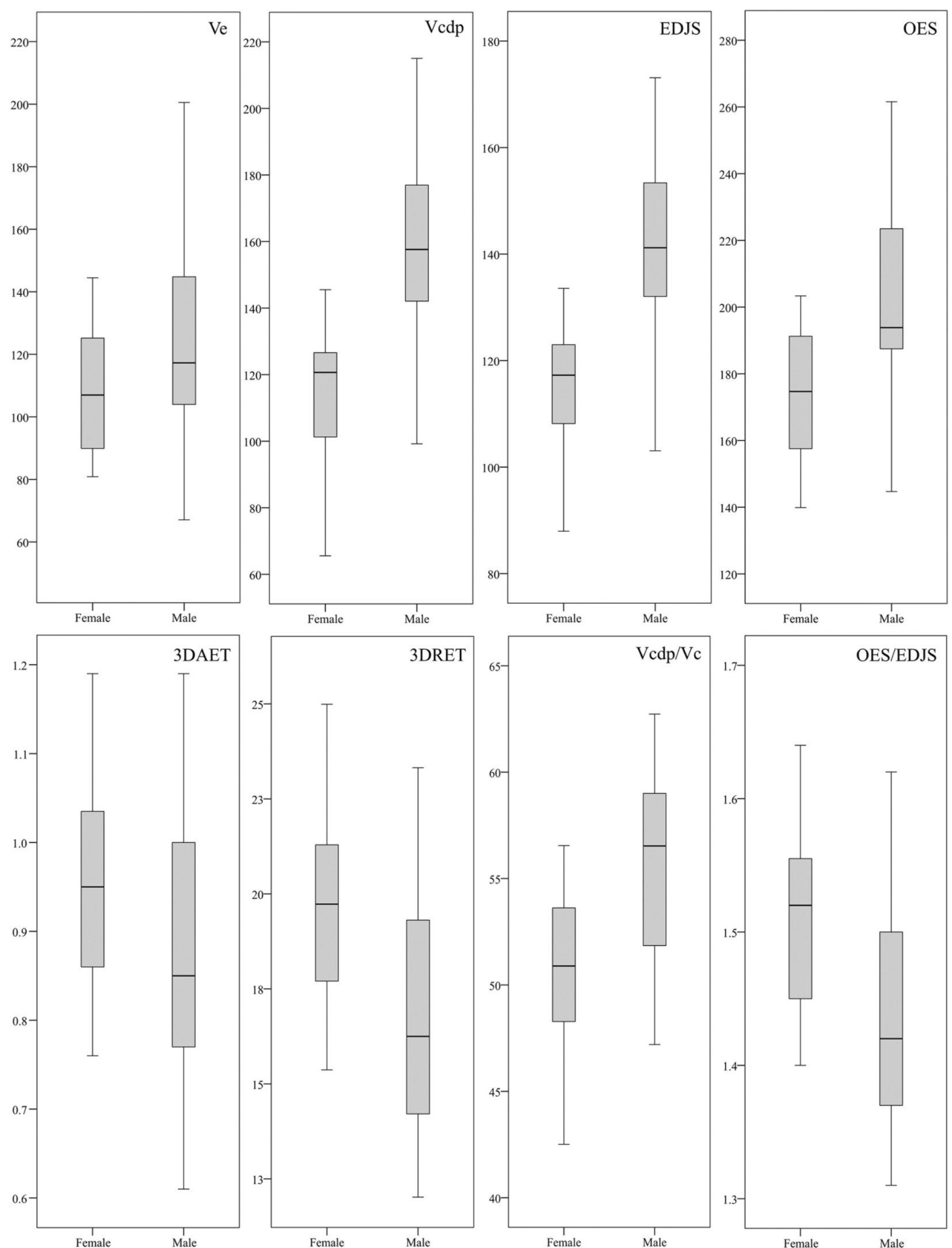
Figure 2. Standard box and whisker plot of the upper canine tissue proportions (wear stages 1-3). This graph represents the interquartile range (25th-75th percentiles: Boxes), 1.5 interquartile ranges (whiskers) and the median values (black line). Outliers are signified with circles and asterisks

Table 2. Discriminant function analysis results a obtained from sub-sample of slightly worn maxillary canines $(n=40)$

\begin{tabular}{|c|c|c|c|c|c|c|c|}
\hline \multirow[t]{2}{*}{ Variables } & \multicolumn{3}{|c|}{ Unstandardized coefficients } & \multirow[b]{2}{*}{ D4 } & \multirow[b]{2}{*}{ D5 } & \multirow[b]{2}{*}{ D6 } & \multirow[b]{2}{*}{ D7 } \\
\hline & D1 & D2 & D3 & & & & \\
\hline $\mathrm{Vc}$ & - & - & - & - & 0.025 & - & - \\
\hline $\mathrm{Vr}$ & - & - & - & - & 0.005 & - & - \\
\hline $\mathrm{Vt}$ & - & - & - & - & - & - & - \\
\hline $\mathrm{Ve}$ & - & - & - & - & - & - & 0.142 \\
\hline Vcdp & 0.041 & - & - & - & - & - & -0.044 \\
\hline EDJS & - & - & 0.062 & - & -0.050 & - & 0.073 \\
\hline OES & - & - & - & - & -0.035 & - & -0.033 \\
\hline $\mathrm{BS}$ & - & - & - & 0.195 & 0.128 & 0.164 & 0.142 \\
\hline Vtdp & - & 0.011 & - & - & 0.004 & - & - \\
\hline $\mathrm{Vc} / \mathrm{Vt}$ & - & - & - & - & 0.096 & - & - \\
\hline 3DAET & - & - & - & - & - & - & -39.705 \\
\hline 3DRET & - & - & - & - & - & - & 2.507 \\
\hline Vcdp/Vc & - & - & - & - & - & 0.120 & 1.074 \\
\hline OES/EDJS & - & - & - & - & -9.671 & - & - \\
\hline
\end{tabular}


Variables

\begin{tabular}{|llllllll|} 
& D1 & D2 & D3 & D4 & D5 & D6 & D7 \\
Constant & -5.577 & -5.506 & -8.019 & -7.499 & 8.192 & -12.702 & -85.546 \\
Sectioning point (S.P.) & 0.000 & 0.000 & 0.000 & 0.000 & 0.000 & 0.000 & 0.000 \\
Eigenvalue & 0.810 & 0.759 & 0.630 & 1.047 & 1.467 & 1.376 & 1.712 \\
Can. Corre. & 0.669 & 0.657 & 0.622 & 0.715 & 0.771 & 0.761 & 0.794 \\
Wilk's lambda & 0.552 & 0.569 & 0.614 & 0.488 & 0.405 & 0.421 & 0.369 \\
$F$ value (sig.) & $\mathbf{. 0 0 0}$ & $\mathbf{. 0 0 0}$ & $\mathbf{. 0 0 0}$ & $\mathbf{. 0 0 0}$ & $\mathbf{. 0 0 0}$ & $\mathbf{. 0 0 0}$ & $\mathbf{. 0 0 0}$ \\
\hline
\end{tabular}

Significant $p$ values in bold.

Table 3. Sex allocation accuracy (\%) for each discriminant function generated from data collected in this study, tested on the original sample and using cross-validation. The functions were also tested on a hold-out sample of slightly worn teeth. Discriminant function scores were calculated using the raw coefficients multiplied by the corresponding dental dimensions plus the constant. The resulting score was compared with the sectioning point. If the score was greater than the sectioning point the sex was determined to be male

Tested on equations sample

Original functions

\begin{tabular}{|llllllllll|}
\hline D1 & $94.70 \%$ & $81.00 \%$ & $\mathbf{8 7 . 5 0 \%}$ & $94.70 \%$ & $81.00 \%$ & $\mathbf{8 7 . 5 0 \%}$ & $87.50 \%$ & $87.50 \%$ & $\mathbf{8 7 . 5 0 \%}$ \\
D2 & $78.90 \%$ & $90.50 \%$ & $\mathbf{8 5 . 0 0 \%}$ & $73.70 \%$ & $85.70 \%$ & $\mathbf{8 0 . 0 0 \%}$ & $87.50 \%$ & $87.50 \%$ & $\mathbf{8 7 . 5 0 \%}$ \\
D3 & $89.50 \%$ & $76.20 \%$ & $\mathbf{8 2 . 5 0 \%}$ & $89.5 \%$ & $76.20 \%$ & $\mathbf{8 2 . 5 0 \%}$ & $87.50 \%$ & $87.50 \%$ & $\mathbf{8 7 . 5 0 \%}$ \\
\hline
\end{tabular}


Tested on equations sample

Original

Discriminant Female functions
Tested on hold-out sample

Cross-validation

Slightly worn teeth

Total Female Male Total

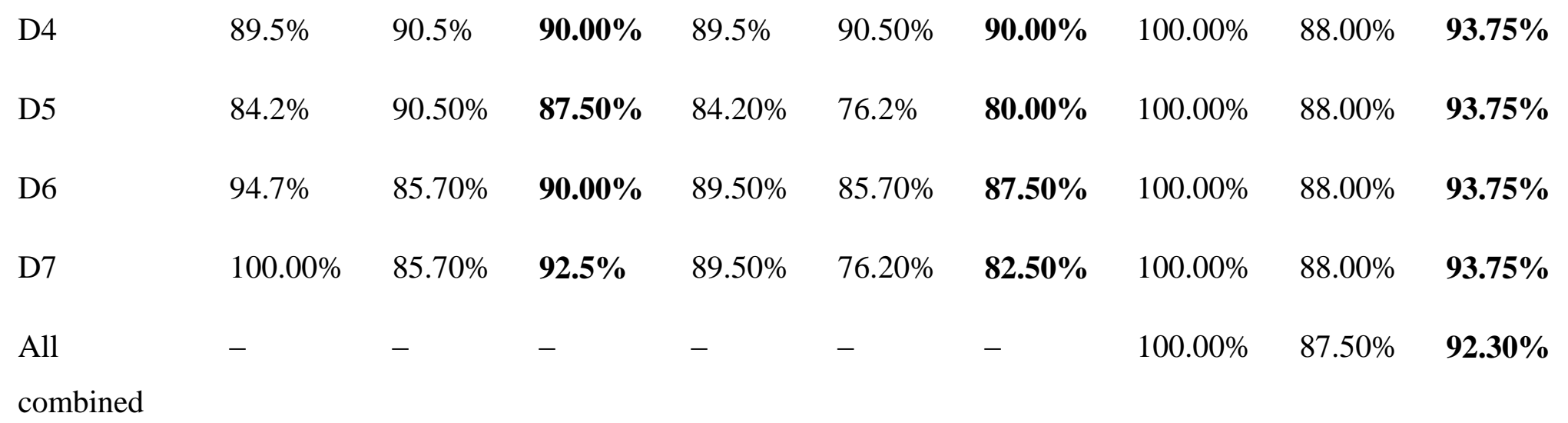

\subsection{Intra-population variability}

The Kolmogorov-Smirnov test showed that all dimensions were normally distributed within each sex category. The results of the homogeneity of variance test indicate that the sample is statistically homogeneous for all dimensions and indices, except for the enamel volume (Ve), the EDJ surface area (EDJS), the outer enamel surface area (OES), and the index Vc/Vt. In these cases, a Student's $t$ test was applied (indicated with an asterisk in Table 1); an ANCOVA test could not be applied to compare the means for these variables.

All absolute tooth dimensions were larger in males and the mean comparison analysis showed that these differences were statistically significant (Table 1). The relative measurements associated with these absolute variables also showed statistically significant differences, except for average enamel thickness (3DAET). The relative enamel thickness (3DRET) lets us observe that females have significantly thicker enamel than males. The same happens with the OES, which is significantly greater in females in relation to their EDJ surface area, indicated by the OES/EDJS index. Therefore, although the ANCOVA test could not be applied to enamel volume (Ve), these indices (3DRET and OES/EDJS) show that the enamel seems to have relatively larger dimensions in females than in males. ANCOVA tests could be applied to dentine volume 
measurements (Vcdp, Vtdp), as well as to the basal surface area of the crown (BS). The results of this test shows that these three variables were significantly larger in males even after controlling for size $(\mathrm{Vt})$. This is corroborated by the relative dentine volume (Vcdp/Vc) results, supporting that males have absolutely, but also relatively, more dentine than females.

3.2 Discriminant function analysis

Table 2 includes the unstandardized discriminant function coefficients, constants, sectioning points and main statistical values obtained from DFA. This analysis produced a set of univariate and multivariate functions, seven of which have high percentages of correct determinations and were selected consequently. Four univariate functions were included, which were based on the following variables: the coronal dentine and pulp volume (D1), the total dentine and pulp volume (D2), the EDJ surface area (D3), and the basal surface area (D4). Furthermore, a multivariate analysis that used all the measured variables and associated indices was carried out (D5), as well as a second one that employed the variables and indices from the crown (D7). We also created multivariate equations using all variables and indices through a stepwise DFA using the Wilks' lambda method (D6). All functions were statistically significant in discriminating between groups $(F$ value, $p<.01)$.

Table 3 shows the sex allocation accuracy (\%) for each discriminant function, tested on the original sample used for the creation of the functions $(n=40)$ and via the cross-validation technique, as well as on a hold-out sample of slightly worn teeth $(n=16)$. The percentage of correct determinations for the univariate functions ranged between $82.50 \%$ and $90.00 \%$ for the original sample and the cross-validated analysis, and between $87.50 \%$ and $93.75 \%$ for the holdout sample validation. On the other hand, multivariate equations had a classification accuracy that ranged between $87.50 \%$ and $92.50 \%$ for the original sample, between $80.00 \%$ and $87.50 \%$ for the cross-validated analysis, and was $93.75 \%$ for the hold-out sample validation. The function with the greatest correct sex allocation was D4, generated from the basal surface area of the crown. We also used a combination of the seven functions (D1-D7) in the hold-out sample, assigning each individual to a specific sex when at least four of the outcomes indicated either "male" or "female". Using this methodology, we obtained $92.30 \%$ correct classifications.

Both sexes were not classified with the same accuracy by all discriminant functions. Overall, the percentage of correct classifications was higher in females than in males, except for functions D2 (Vtdp) and D4 (BS). The percentage of correct determinations in the original sample ranges 
between $76.20 \%$ and $90.50 \%$ in the case of males and between $78.90 \%$ and $100 \%$ in the case of females. The cross-validation test results ranged between $76.20 \%$ and $90.50 \%$ in the case of males and between $73.70 \%$ and $94.70 \%$ in the case of females. Validation of the hold-out sample ranged between $87.50 \%$ and $88.00 \%$ in the case of males and between $87.50 \%$ and $100.00 \%$ in the case of the females. The combination of the results from the seven functions correctly classified $100 \%$ of the females and $87.5 \%$ of the males.

\section{DISCUSSION}

4.1 Sexual dimorphism of maxillary canines

Teeth are the most resistant tissue of the human body, which is why they have been the focus of anthropological research. In forensic sciences, teeth have been used mostly for age estimation (Cameriere et al., 2006; Someda et al., 2009; Stavrianos, Mastagas, Stavrianou, \& Karaiskou, 2008) and sex determination (Acharya \& Mainali, 2007; Ateş et al., 2006; Pereira et al., 2010; Zorba et al., 2012), with most of these odontometric studies using discriminant function statistical models to assess sexual dimorphism in human dentition.

The sexual dimorphism of permanent teeth has been established by many researchers, being the greatest in canines (Harris \& Bailit, 1988; Hillson, 1996b; Işcan \& Kedici, 2003; Peckmann et al., 2015). These differences take the form of a marked difference in size, with male canines being more volumetric than those of females (De Angelis et al., 2015, García-Campos et al., 2018). Most of the studies in which the sexual dimorphism of canines has been assessed are based on traditional MD and BL crown diameters (Acharya \& Mainali, 2007; Ateş et al., 2006; Ditch \& Rose, 1972; Işcan \& Kedici, 2003; Moorrees, Kai-Jen Yen, Moorrees, \& Thomsen, 1957; Sabóia et al., 2013). However, these measurements usually are modified by wear and pathologies, so some authors have explored alternative variables like the cervical MD and BL diameters as well as diagonal diameters of the crown (Hillson, FitzGerald, \& Flinn, 2005; Viciano, Alemán, D'Anastasio, Capasso, \& Botella, 2011; Viciano, López-Lázaro, \& Alemán, 2013; Zorba, Moraitis, \& Manolis, 2011). All such dimensions have been found to be sexually dimorphic, reaching allocation accuracies in the original sample ranging from $67 \%$ to $88 \%$, approximately.

The results of the present study corroborate the differences in size observed in previous studies (Table 1). The male maxillary canines showed a significantly greater volume (Vt) than those of 
their female counterparts. Their crowns are more volumetric $(\mathrm{Vc})$, showing very significant differences to those of the females. These differences in crown size are also reflected in their coronal basal surface (BS), showing absolutely and relatively larger areas in males. All these agree with the results obtained from coronal linear measurements (Viciano et al., 2011, 2013; Zorba et al., 2011) as well as those from mandibular canine volumes (García-Campos et al., 2018). Not only are the crowns of female maxillary canines smaller, but so are their roots (Vr). The study of root measurements in the context of sexual dimorphism has greatly expanded in recent years (Garn, Van Alstine Jr, \& Cole, 1978; Zorba, Vanna, \& Moraitis, 2013). Roots tend to be better preserved compared to crowns, as they are protected by the alveolar bone; in addition, they are far less frequently affected by pathological conditions or wear. Zorba et al. (2013) tested the existence of sexual dimorphism in the root length of single-rooted teeth and showed that root length was greater in males than in females (allocation accuracy in the original sample: $77 \%-88 \%$ ). In the light of the results of the present and previous studies (García-Campos et al., 2018), it can be confirmed that canine roots are not only longer in males but also more volumetric, representing a greater percentage of their total volume $(\mathrm{Vc} / \mathrm{Vt})$ in contrast to female canines.

Hypotheses proposed for tooth-size dimorphism between males and females include: a greater enamel thickness owing to a longer period of amelogenesis in males (Acharya \& Mainali, 2008); a relatively higher quantity of dentine in male teeth (García-Campos et al., 2018; Schwartz \& Dean, 2005; Smith, Olejniczak, Reid, Ferrell, \& Hublin, 2006); or, differential effects of sex chromosomes and hormonal influences in promoting dental tissue growth (Alvesalo, 2009; Alvesalo, Tammisalo, \& Townsend, 1991; Guatelli-Steinberg et al., 2008; Pentinpuro et al., 2017; Pentinpuro, Lähdesmäki, Niinimaa, Pesonen, \& Alvesalo, 2014; Ribeiro, Brook, Hughes, Sampson, \& Townsend, 2013; Ribeiro, Sampson, Hughes, Brook, \& Townsend, 2012; Smith et al., 2006). That is the reason why, whereas most odontometric studies were focused on crown size differences, some researchers have attempted to quantify tissue differences between sexes (Feeney, 2009; Harris \& Hicks, 1998; Saunders et al., 2007; Schwartz \& Dean, 2005; Smith et al., 2006; Stroud et al., 1994). Schwartz and Dean (2005) and Saunders et al. (2007) provided enamel thickness values obtained from physical sections of mandibular canines, including the first study also third molars. Variation in lateral enamel thickness has also been examined through clinical radiographs of maxillary incisors (Harris \& Hicks, 1998) and 
mandibular premolars (Stroud et al., 1994). Two more recent studies employed 3D models obtained from micro-CT scanning. In the first of these, Feeney et al. (2010) employed virtual sections to quantify the average enamel thickness of a sample of clinically extracted Indonesian canine and premolar teeth. In the second, García-Campos et al. (2018), using the same methodology applied in the present study, determined the degree of sexual dimorphism in the dental tissue volumes and surface areas of mandibular canines. Although all these studies vary in terms of the tooth class assessed, overall it is observed to a greater or lesser extent similar patterns of sexual dimorphism in dental tissue proportions: male teeth have greater dentine component, whereas in females the enamel is thicker (Feeney et al., 2010; García-Campos et al., 2018; Saunders et al., 2007; Schwartz \& Dean, 2005; Smith et al., 2006; Stroud et al., 1994). The results of the present study confirm this pattern. As in the case of lower canines (GarcíaCampos et al., 2018), male maxillary canines have absolutely (Vcdp, Vtdp) and relatively (Vcdp/Vc, ANCOVA results) more dentine than those of females, whereas females have been found to have relatively thicker enamel (3DRET). In contrast to the lower canines, the enamel cap volume was smaller in female upper canines when compared to that of males. However, although the ANCOVA test could not be applied to this variable, the 3DRET index results lend support to the idea that this may be due to the differences in size between sexes, and not because males have a proportionally greater amount of enamel. As with tissue volumes, the surface areas of enamel (OES) and dentine (EDJS) are smaller in females; nevertheless, in both upper and lower canines their OES have a significantly larger area regarding the EDJ surface (OES/EDJS index) (García-Campos et al., 2018, present study), which has been related to greater enamel thickness by some authors (Smith et al., 2006).

4.2 Sex allocation accuracy of the discriminant functions based on dental tissue volumes and surface areas of maxillary canines

DFA has become a method extensively used by archaeologists and forensic anthropologists to determine sex (Acharya \& Mainali, 2007; García-Campos et al., 2018; Hassett, 2011; Işcan \& Kedici, 2003; Viciano et al., 2011, 2013; Zorba et al., 2013), as it calculates the optimal combination of variables and indices to reflect their contribution to sex diagnosis. Univariate functions selected in this study are defined by the following variables: the coronal dentine and pulp volume (Vcdp, D1); the total dentine and pulp volume (Vtdp, D2); the EDJ surface area (EDJS, D3); and the basal surface area of the crown (BS, D4). Most of these 
variables are related to the dentine component, highlighting its importance in sex determination. Overall, multivariate functions (D5, D6, and D7) have higher accuracy than univariate ones (original: 87.5\%-92.50\%; cross-validation: 80.00\%-82.50\%; hold-out sample: $93.75 \%$ ), although the univariate function D4 was the most effective in sex diagnosis. The percentage of correct determinations when we combined all functions was $92.30 \%$, which, together with the previous results, shows the effectiveness of the methodology introduced in this study, which overtakes that of methods based on linear measurements. The discriminant function results obtained for upper canines were similar to those obtained for lower canines (García-Campos et al., 2018). It should be pointed out that in both tooth classes the functions based on BS and Vtdp were selected due to their high accuracy rates. As in the case of mandibular canines (García-Campos et al., 2018), as well as the results of previous researches (Acharya \& Mainali, 2007; Ateş et al., 2006; Işcan \& Kedici, 2003), in general terms females were correctly assigned more often than males, which may indicate greater variability in male maxillary canines.

4.3 The potential of the methodology exposed for sex determination and its limitations Sex determination in fragmented human remains constitutes the foremost step for identification in physical anthropology. The pelvis and skull have been shown to be the most accurate skeletal elements for determining sex (Ferembach et al., 1980; İşcan, 2005; Iscan, Derrick, Iscan, \& Derrick, 1984; Phenice, 1969). However, in both forensic practice and an archaeological context it is common to recover human remains where most skeletal structures appear fractured or are absent. An alternative is to use teeth. Considering the fact that teeth are the most resistant mineral components of the human skeleton (Hillson, 1996b), a method based on dental measurements may help to fill this gap. The results of the present study and previous research show that there are several dental variables that can be used to develop sample-specific methods for sex determination, and that the correct allocation accuracies that they achieve are comparable to other metric methods commonly applied to other skeletal elements (Acharya \& Mainali, 2007; Ateş et al., 2006; García-Campos et al., 2018; Hassett, 2011; Zorba et al., 2013). Their application might be especially useful in sex determination of subadult individuals. This is because the crowns of the permanent dentition develop early, and once formed, they hardly change during growth. This means that any discriminant function created from their measurement, and which is powerful at discriminating between sexes, could also be useful in subadults for whom secondary sex characteristics of the skeleton are not yet discernible. In particular, techniques based on 
permanent canine traits might allow us to determine the sex of individuals older than 6 years of age, which is the age around which the crown finishes its formation (Moorrees, Fanning, \& Hunt, 1963). One limitation is that these functions cannot be employed to determine the sex of very young individuals whose permanent teeth have not yet formed. Although deciduous crown dimensions seem to show considerably less sexual dimorphism than permanent teeth (Black, 1978; De Vito \& Saunders, 1990), future studies of dental tissue proportions of primary dentition in general, and of deciduous canines in particular, could help to shed light on this issue. The usefulness in sex estimation studies of the multivariate methods based on linear dimensions of the canines has been deeply explored, which have obtained an accuracy which ranges from 67\% to 88.2\% (e.g., Ateş et al., 2006; Işcan \& Kedici, 2003; Karaman, 2006; Peckmann et al., 2015; Zorba et al., 2013). In contrast to these studies, the methodology based on 3D measurements proposed here confidently offers greater percentages of correct assignment, which has been assessed employing geographical mixed samples and tested in a hold-out sample. On the other hand, a limitation of sex determination methodologies based on linear odontometric measurements is that teeth should not be extremely worn down nor should their dimensions be affected by dental anomalies and disease. In many dental samples, adult teeth show a severe interproximal attrition and/or crown reduction, making it impossible to collect the traditional linear measurements of the crown (MD, BL); yet, the cervical dimensions of the crown can be used as an alternative to solve this problem (Hillson et al., 2005; Viciano et al., 2011, 2013; Zorba et al., 2011). The variables considered in this study might be also be affected by wear. García-Campos et al. (2018) included extensively worn teeth (4-5 wear degree, Molnar, 1971) as a hold-out sample, showing that although the percentage of correct assignment only decreased to 9.64\% compared to the slightly worn sample, the differences between males and females increased, which made them doubt the precision of this methodology as wear increases. A solution to this problem may be the discriminant function based on the basal surface area of the crown (BS), as in both maxillary and mandibular permanent canines the univariate functions created using this variable have high accuracy rates. As with cervical margins diameters, the basal surface is not affected by wear and could be assessed even when the root is either absent, which could be common in single rooted teeth, or is not completed (as with subadult individuals).

\section{CONCLUSIONS}


In light of the findings of the present study, as well as those in literature, it can be affirmed that canine dental tissue proportions provide several variables that can be used to develop methods for sex determination, whose correct allocation accuracies are comparable to other metric methods commonly applied to other skeletal structures. The results of this study show that male maxillary canines have an absolutely and relatively greater dentine component, whereas female enamel is thicker, leading to a difference in dental size in favor of males. These differences have permitted the development of a discriminant function model that achieves correct assignation rate of 92.30\%. This represents an alternative methodology that might become of interest when DNA and other skeletal elements are not available, or in the case of subadults, for whom secondary sexual characteristics cannot always be discerned accurately using techniques based on postcranial measurements or morphological features.

\section{ACKNOWLEDGMENTS}

This study has been carried out thanks to the Dirección General de Investigación of the Spanish Ministerio de Economía y Competitividad (MINECO/FEDER) support, grant number: CGL201565387-C3-1, 3-P. Likewise, we also wish to acknowledge The Leakey Foundation for the funds provided by Gordon Getty and Dub Crook to one of the authors (MM-T). CG-C and MM-M are funded by a doctoral grant from the Junta de Castilla y León, financed in turn by the European Social Funds through the Consejería de Educacion. MMP is the recipient of a post-doctoral research grant at the Atapuerca Foundation. LM-F received financial support from the French State as part of the 'Investments for the future' Programme IdEx Bordeaux, reference ANR-10IDEX-03-02. Some of the micro-CT images were obtained in the Laboratory of Microscopy of the CENIEH-ICTS (Spain) and in collaboration with CENIEH staff. The remaining dental samples were scanned in the Multidisciplinary Laboratory of the International Centre for Theoretical Physics (ICTP) in Trieste in collaboration with Federico Bernardini and Claudio Tuniz. The African sample from Sudan was provided by Dr. Christopher Dean from the Anatomy Department at University College London. Part of the sample was analyzed in the Anthropology Department at University College London in collaboration with Dr. Christopher Soligo. We are indebted to A. Oettlé, G. Krüger and E.N. L'Abbé for kindly authorizing access to the Pretoria Bone Collection (PBC) of the University of Pretoria. We also deeply thank F. de Beer and J. 
Hoffman for carrying out the X-ray micro-CT imaging of the human specimens from the PBC included in this study.

\section{References}

Acharya, A. B., \& Mainali, S. (2007). Univariate sex dimorphism in the Nepalese dentition and the use of discriminant functions in gender assessment. Forensic Science International, 173, $47-56$.

Acharya, A. B., \& Mainali, S. (2008). Are dental indexes useful in sex assessment? The Journal of Forensic Odonto-Stomatology, 26, 53- 59.

Alvesalo, L. (1997). Sex chromosomes and human growth. A dental approach. Human Genetics, $101,1-5$.

Alvesalo, L. (2009). Human sex chromosomes in oral and craniofacial growth. Archives of Oral Biology, 54, S18- S24.

Alvesalo L, Portin P. 1980. 47, XXY males: Sex chromosomes and tooth size. American Journal of Human Genetics 32: 955- 959.

Alvesalo, L., Tammisalo, E., \& Hakola, P. (1985). Enamel thickness in 47,XYY males' permanent teeth. Annals of Human Biology, 12, 421- 427.

Alvesalo, L., Tammisalo, E., \& Townsend, G. (1991). Upper central incisor and canine tooth crown size in 47,XXY males. Journal of Dental Research, 70, 1057- 1060.

Ateş, M., Karaman, F., Işcan, M. Y., \& Erdem, T. L. (2006). Sexual differences in Turkish dentition. Legal Medicine (Tokyo, Japan), 8, 288- 292.

Benazzi, S., Panetta, D., Fornai, C., Toussaint, M., Gruppioni, G., \& Hublin, J.-J. (2014). Technical note: Guidelines for the digital computation of 2D and 3D enamel thickness in hominoid teeth. American Journal of Physical Anthropology, 153, 305- 313.

Black, T. K. (1978). Sexual dimorphism in the tooth-crown diameters of the deciduous teeth. American Journal of Physical Anthropology, 48, 77- 82.

Cameriere, R., Brogi, G., Ferrante, L., Mirtella, D., Vultaggio, C., Cingolani, M., \& Fornaciari, G. (2006). Reliability in age determination by pulp/tooth ratio in upper canines in skeletal remains. Journal of Forensic Sciences, 51, 861- 864.

Cardoso, H. F. V. (2010). Testing discriminant functions for sex determination from deciduous teeth. Journal of Forensic Science, 55, 1557- 1560. 
De Angelis, D., Gibelli, D., Gaudio, D., Cipriani Noce, F., Guercini, N., Varvara, G., Sguazza, E., Sforza, C., Cattaneo C. (2015). Sexual dimorphism of canine volume: A pilot study. Legal Medicine, 17, 163-166.

De Vito, C., \& Saunders, S. R. (1990). A discriminant function analysis of deciduous teeth to determine sex. Journal of Forensic Sciences, 35, 845- 858.

Ditch, L. E., \& Rose, J. C. (1972). A multivariate dental sexing technique. American Journal of Physical Anthropology, 37, 61- 64.

Elamin, F., \& Liversidge, H. M. (2013). Malnutrition has no effect on the timing of human tooth formation. PLoS One, 8, e72274.

Feeney, R. N., Zermeno, J. P., Reid, D. J., Nakashima, S., Sano, H., Bahar, A., ... Smith, T. M. (2010). Enamel thickness in Asian human canines and premolars. Anthropological Science, $118,191-198$.

Feeney RNM. 2009. Microtomographic analysis of sexual dimorphism and dental tissue distribution in human molars. The Ohio State University, Columbus.

Ferembach, D., Schwindezky, I., Stoukal, M., Ferembach, D., Schwindezky, I., \& Stoukal, M. (1980). Recommendation for age and sex diagnoses of skeletons. Journal of Human Evolution, 9, 517- 549.

García-Campos, C., Martinón-Torres, M., Martín-Francés, L., Martínez de Pinillos, M., ModestoMata, M., Perea-Pérez, B., ... Bermúdez de tro, J. M. (2018). Contribution of dental tissues to sex determination in modern human populations. American Journal of Physical Anthropology, $166,459-472$.

Garn, S. M., Lewis, A. B., \& Kerewsky, R. S. (1967). Shape similarities throughout the dentition. Journal of Dental Research, 46, 1481.

Garn, S. M., Van Alstine, W. L., Jr., \& Cole, P. E. (1978). Relationship between root lengths and crown diameters of corresponding teeth. Journal of Dental Research, 57, 636.

Guatelli-Steinberg, D., Sciulli, P. W., \& Betsinger, T. K. (2008). Dental crown size and sex hormone concentrations: Another look at the development of sexual dimorphism. American Journal of Physical Anthropology, 137, 324- 333.

Harris, E. F., \& Bailit, H. L. (1988). A principal components analysis of human odontometrics. American Journal of Physical Anthropology, 75, 87- 99. 
Harris, E. F., \& Hicks, J. D. (1998). A radiographic assessment of enamel thickness in human maxillary incisors. Archives of Oral Biology, 43, 825-831.

Harris, E. F., Hicks, J. D., \& Barcroft, B. D. (2001). Tissue contributions to sex and race:

Differences in tooth crown size of deciduous molars. American Journal of Physical Anthropology, 115, 223- 237.

Hassett, B. (2011). Technical note: Estimating sex using cervical canine odontometrics: A test using a known sex sample. American Journal of Physical Anthropology, 146, 486- 489.

Hillson, S. (1996a). Dental anthropology. Cambridge: Cambridge University Press Available from: http://discovery.ucl.ac.uk/1358908/

Hillson, S. (1996b). Dental anthropology. Cambridge: Cambridge University Press.

Hillson, S., FitzGerald, C., \& Flinn, H. (2005). Alternative dental measurements: Proposals and relationships with other measurements. American Journal of Physical Anthropology, 126, 413- 426.

İşcan, M. Y. (2005). Forensic anthropology of sex and body size. Forensic Science International, $147,107-112$.

Iscan MY, Derrick K, Iscan MY, Derrick K. 1984. Determination of sex from the sacroiliac joint: A visual assessment technique. Florida Scientist, 47, 94-98.

Işcan, M. Y., \& Kedici, P. S. (2003). Sexual variation in bucco-lingual dimensions in Turkish dentition. Forensic Science International, 137, 160- 164.

Karaman, F. (2006). Use of diagonal teeth measurements in predicting gender in a Turkish population. Journal of Forensic Sciences, 51, 630-635.

Lund, H., \& Mörnstad, H. (1999). Gender determination by odontometrics in a Swedish population. The Journal of Forensic Odonto-Stomatology, 17, 30- 34.

Molnar, S. (1971). Human tooth wear, tooth function and cultural variability. American Journal of Physical Anthropology, 34, 175- 189.

Molnar, S., Hildebolt, C., Molnar, I. M., Radovcic, J., \& Gravier, M. (1993). Hominid enamel thickness: I. The Krapina Neandertals. American Journal of Physical Anthropology, 92, 131138.

Moorrees, C. F. A., Fanning, E. A., \& Hunt, E. E. (1963). Age variation of formation stages for ten permanent teeth. Journal of Dental Research, 42, 1490- 1502. 
Moorrees, E., Kai-Jen Yen, P., Moorrees, C. F., \& Thomsen, S. O. (1957). Mesiodistal crown diameters of the deciduous and permanent teeth in individuals. Journal of Dental Research, 36, $39-47$.

Olejniczak, A. J., Smith, T. M., Feeney, R. N. M., Macchiarelli, R., Mazurier, A., Bondioli, L., ... Hublin, J.-J. (2008). Dental tissue proportions and enamel thickness in Neandertal and modern human molars. Journal of Human Evolution, 55, 12- 23.

Olejniczak, A. J., Tafforeau, P., Feeney, R. N. M., \& Martin, L. B. (2008). Three-dimensional primate molar enamel thickness. Journal of Human Evolution, 54, 187- 195.

Peckmann, T. R., Logar, C., Garrido-Varas, C. E., Meek, S., \& Pinto, X. T. (2015). Sex determination using the mesio-distal dimension of permanent maxillary incisors and canines in a modern Chilean population. Science \& Justice. 56, 84-89.

Pentinpuro, R., Pesonen, P., Alvesalo, L., \& Lähdesmäki, R. (2017). Crown heights in the permanent teeth of 47,XYY males. Acta Odontologica Scandinavica, 75, 379-385.

Pentinpuro, R. H., Lähdesmäki, R. E., Niinimaa, A. O., Pesonen, P. R. O., \& Alvesalo, L. J. (2014). Crown heights in the permanent teeth of 45,X and 45,X/46,XX females. Acta Odontologica Scandinavica, 72, 908-916.

Pereira, C., Bernardo, M., Pestana, D., Santos, J. C., \& de, M. M. C. (2010). Contribution of teeth in human forensic identification-Discriminant function sexing odontometrical techniques in Portuguese population. Journal of Forensic and Legal Medicine, 17, 105- 110.

Phenice, T. W. (1969). A newly developed visual method of sexing the os pubis. American Journal of Physical Anthropology, 30, 297-301.

Rao, N. G., Rao, N. N., Pai, M. L., \& Kotian, M. S. (1989). Mandibular canine index-A clue for establishing sex identity. Forensic Science International, 42, 249- 254.

Ribeiro, D., Sampson, W., Hughes, T., Brook, A., \& Townsend, G. (2012). Sexual dimorphism in the primary and permanent dentitions of twins: An approach to clarifying the role of hormonal factors. New Directions in Dental Anthropology Paradigms, Methodologies and Outcomes, $46-64$.

Ribeiro, D. C., Brook, A. H., Hughes, T. E., Sampson, W. J., \& Townsend, G. C. (2013). Intrauterine hormone effects on tooth dimensions. Journal of Dental Research, 92, 425-431. 
Sabóia, T. M., Tannure, P. N., Luiz, R. R., Costa M de, C., Granjeiro, J. M., Küchler, E. C., \& Antunes, L. S. (2013). Sexual dimorphism involved in the mesiodistal and buccolingual dimensions of permanent teeth. Dentistry 3000, 1, 2-6.

Saunders, S. R., Chan, A. H. W., Kahlon, B., Kluge, H. F., \& FitzGerald, C. M. (2007). Sexual dimorphism of the dental tissues in human permanent mandibular canines and third premolars. American Journal of Physical Anthropology, 133, 735- 740.

Schwartz, G. T., \& Dean, M. C. (2005). Sexual dimorphism in modern human permanent teeth. American Journal of Physical Anthropology, 128, 312- 317.

Shellis, R. P., Beynon, A. D., Reid, D. J., \& Hiiemae, K. M. (1998). Variations in molar enamel thickness among primates. Journal of Human Evolution, 35, 507- 522.

Skinner, M. M., Gunz, P., Wood, B. A., \& Hublin, J.-J. (2008). Enamel-dentine junction (EDJ) morphology distinguishes the lower molars of Australopithecus africanus and Paranthropus robustus. Journal of Human Evolution, 55, 979- 988.

Skinner, M. M., Wood, B. A., Boesch, C., Olejniczak, A. J., Rosas, A., Smith, T. M., \& Hublin, J.-J. (2008). Dental trait expression at the enamel-dentine junction of lower molars in extant and fossil hominoids. Journal of Human Evolution, 54, 173- 186.

Smith, T. M., Olejniczak, A. J., Reh, S., Reid, D. J., \& Hublin, J.-J. (2008). Brief communication: Enamel thickness trends in the dental arcade of humans and chimpanzees. American Journal of Physical Anthropology, 136, 237- 241.

Smith, T. M., Olejniczak, A. J., Reid, D. J., Ferrell, R. J., \& Hublin, J. J. (2006). Modern human molar enamel thickness and enamel-dentine junction shape. Archives of Oral Biology, 51, 974- 995 .

Smith, T. M., Olejniczak, A. J., Zermeno, J. P., Tafforeau, P., Skinner, M. M., Hoffmann, A., ... Hublin, J.-J. (2012). Variation in enamel thickness within the genus homo. Journal of Human Evolution, 62, 395-411.

Someda, H., Saka, H., Matsunaga, S., Ide, Y., Nakahara, K., Hirata, S., \& Hashimoto, M. (2009). Age estimation based on three-dimensional measurement of mandibular central incisors in Japanese. Forensic Science International, 185, 110- 114.

Stavrianos, C., Mastagas, D., Stavrianou, I., \& Karaiskou, O. (2008). Dental age estimation of adults: A review of methods and principals. Research Journal of Medical Sciences, 2, 258268. 
Stroud, J. L., Buschang, P. H., \& Goaz, P. W. (1994). Sexual dimorphism in mesiodistal dentin and enamel thickness. Dento Maxillo Facial Radiology, 23, 169- 171.

Viciano, J., Alemán, I., D'Anastasio, R., Capasso, L., \& Botella, M. C. (2011). Odontometric sex discrimination in the Herculaneum sample (79 AD, Naples, Italy), with application to juveniles. American Journal of Physical Anthropology, 145, 97- 106.

Viciano, J., López-Lázaro, S., \& Alemán, I. (2013). Sex estimation based on deciduous and permanent dentition in a contemporary Spanish population. American Journal of Physical Anthropology, 152, 31-43.

Zilberman, U., \& Smith, P. (2001). Sex- and age-related differences in primary and secondary dentin formation. Advances in Dental Research, 15, 42- 45.

Zorba, E., Moraitis, K., Eliopoulos, C., \& Spiliopoulou, C. (2012). Sex determination in modern Greeks using diagonal measurements of molar teeth. Forensic Science International, 217, 1926.

Zorba, E., Moraitis, K., \& Manolis, S. K. (2011). Sexual dimorphism in permanent teeth of modern Greeks. Forensic Science International, 210, 74- 81.

Zorba, E., Vanna, V., \& Moraitis, K. (2013). Sexual dimorphism of root length on a Greek population sample. HOMO-Journal of Comparative Human Biology, 65, 143-154. 